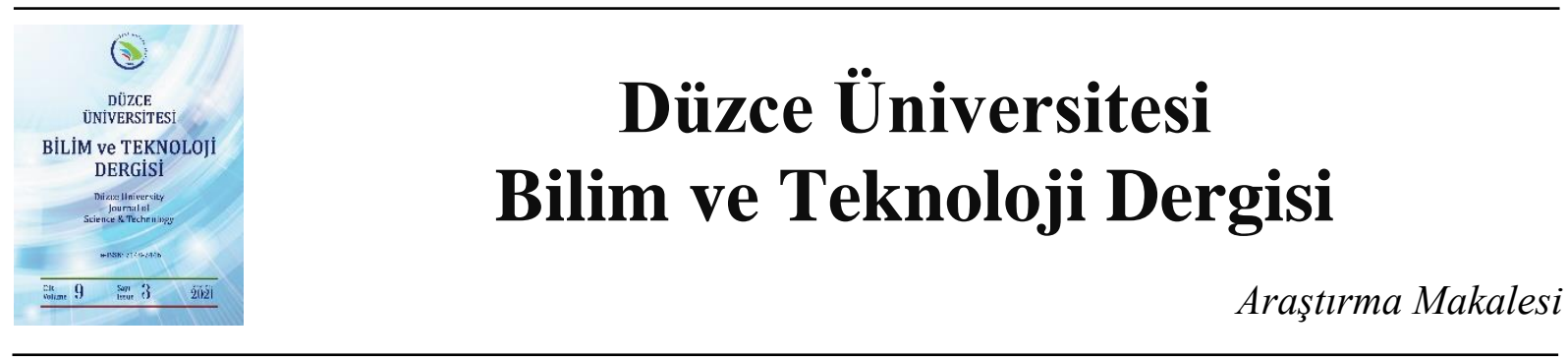

\section{ÇYTHYE-2018 Yönetmeliğine göre I-Enkesitli Eğilme Elemanları için Yardımcı Abaklar}

\author{
Dehmet Bakır BOZKURT ${ }^{\mathrm{a}, *}$ \\ ${ }^{a}$ İnşaat Mühendisliği Bölümü, Mühendislik Fakültesi, Manisa Celal Bayar Üniversitesi, Manisa, TÜRKIYYE \\ * Sorumlu yazarin e-posta adresi: mehmet.bozkurt@cbu.edu.tr
}

DOI: $10.29130 /$ dubited. 820330

\begin{abstract}
ÖZET
Türkiye'de çelik yapıların tasarımı 2016 yılından itibaren Çelik Yapıların Tasarım, Hesap ve Yapım Esasları (ÇYTHYE) yönetmeliği kullanılarak yapılmaktadır. Bu yönetmelik yapısal çelik elemanlarını öncelikle maruz kaldığı iç kuvvetlere göre sınıflandırıp daha sonra bu elemanların boyutlandırılması için ayrı ayrı formüller tanımlamaktadır. Karmaşık formüller münferit çelik elemanların el hesabı ile boyutlandırılması için kullanılabilir görünmesine rağmen, karmaşık yapı sistemlerinin tasarımları için bilgisayar yazılımlarının kullanılması kaçınılmazdır. Bu çalışma güçlü eksenleri etrafında eğilme momentine maruz kalan S235, S275 ve S355 malzeme sınıflarından teşkil edilmiş hadde I-enkesitli profiller için ÇYTHYE yönetmeliğinde tanımlanan yük ve dayanım katsayıları ile tasarım (YDKT) esaslarına göre hazırlanmış yardımcı abaklar sunmaktadır. Güçlü eksenleri etrafında eğilme momentine maruz kalan çelik profillerin basınç başlı̆̆ında yanal yer değiştirmelerinin ve enkesit burulmasının önlendiği noktalar arasındaki eleman uzunluğu, $L_{b}$ 'ye göre tasarım eğilme momenti dayanımlarının değişimlerini veren bu abaklar sayesinde yapısal tasarım mühendisleri hızlı ve etkin bir şekilde eğilme elemanlarını boyutlandırabileceklerdir.
\end{abstract}

Anahtar Kelimeler:ÇYTHYE, Çelik, Yönetmelik, Eğilme elemanı, Abak.

\section{Supplementary Nomograms for Rolled I-Shaped Flexural Members based on SDCCSS-2018}

\begin{abstract}
In Turkey, design of the steel structures has been conducted by using Specification for Design, Calculation and Construction of Steel Structures (SDCCSS) since 2016. This specification first classifies the structural steel members according to their internal forces, and then defines separate formulas to design of these elements. Although the complicated formulas seem to be useful for the design of the individual steel elements by using hand calculation, it is inevitable to use computer software for the design of complex building systems. This study presents supplementary nomograms for the rolled I-shaped flexural members made of S235, S275, and S355 material classes designed based on load and resistance factor design (LRFD) defined in SDCCSS under bending moments about their strong axis. Structural design engineers are able to quickly and efficiently design of the flexural members which are under bending moments about their strong axis thanks to these nomograms indicating variation of the design flexural strength according to $L_{b}$, which is the length of the two points restrained against lateral displacement and torsional movement of the section flange under compression.
\end{abstract}

Keywords:SDCCSS, Steel, Specification, Flexural member, Nomogram

Geliş: 03/11/2020, Düzeltme: 10/03/2021, Kabul: 18/03/2021 


\section{GIRIS}

Ekonomik ve güvenli yapı tasarımı için çelik yapılar bir seri tasarım kuralları içeren yönetmeliklere göre boyutlandırılırlar. Çelik yapıların tasarımı için ilk yönetmelik Amerika Birleşik Devletleri'nde 1923 yılında [1] ve Avrupa'da 1932 yılında [2] yayınlanmasına rağmen Türkiye'de 1980 yılında [3] yayınlanmıştır. Günümüze kadar gerçekleşen birçok bilimsel çalışma ışı̆̆ında yönetmelikler belli aralıklarla güncellenerek yapısal tasarım mühendislerinin hizmetine sunulmuştur. Günümüzde güncel olarak Amerika Birleşik Devletleri'nde "Specification for Structural Steel Buildings, ANSI/AISC 360-16" [4], Avrupa'da "Eurocode 3: Design of steel structures (EN 1993)" [5], Kanada'da "Design of Steel Structures, CSA S16:19" [6], Japonya'da "Standard Specifications for Steel and Composite Structures, JSCE-2007" [7] ve Türkiye' de "Çelik Yapıların Tasarım, Hesap ve Yapımına Dair Esaslar, ÇYTHYE-2018 [8] kullanılmaktadır.

Amerika Birleşik Devletleri ve Avrupa ülkeleri tarafından kullanılan bu uluslararası çelik yapı tasarım yönetmeliklerinin yanı sıra yapısal elemanların veya birleşimlerin boyutlandırılmasında ihtiyaç duyulan birçok abak ve tablolarda yapısal tasarım mühendislerinin hizmetine sunulmak üzere yönetmelik komiteleri, kamu veya özel sektör tarafindan hazırlanmıştır. AISC 360-16 [4] ile uyumlu "Steel Construction Manual" [9] ve Eurocode 3 [5] ile uyumlu "Steel Building Design: Design Data" [10], "Joints in Steel Construction: Simple Joints To Eurocode 3" [11] ve "Joints in Steel Construction: Moment-Resisting Joints To Eurocode 3" [12] yapisal tasarım mühendisleri tarafindan sıklıkla kullanılan en önemli yardımcı dokümanlardır. Ülkemizde ÇYTHYE-2018 [8] ile uyumlu olarak hazırlanmış "Çelik Yapıların Tasarım, Hesap ve Yapım Esaslarına Dair Yönetmelik Hakkında Uygulama Kılavuzu" [13] dokümanı sadece yapısal elemanların ve birleşimlerinin maruz kaldıkları iç kuvvetlere dayalı tasarım kurallarının özetini ve sayısal uygulamalarını sunmasına rağmen yapısal eleman veya birleşimlerin boyutlandırılmasını kolaylaştıracak abak ve tablolar içermemektedir.

$\mathrm{Bu}$ çalışma, 2020 yılında Bozkurt [14] tarafından hazırlanan "Basınç Elemanları için Yardımcı Abaklar" isimli çalışmanın devamı niteliğindedir. Bu kapsamdaÇYTHYE-2018'de [8] tanımlanan YDKT esaslarına göre uygulamada en çok kullanılan S235, S275 ve S355 malzeme sınıflarından teşkil edilmiş HEA, HEB, IPE ve IPN elemanlarının güçlü eksenleri etrafında tasarım eğilme dayanımlarının profillerin basınç başlı̆̆ında yanal yerdeğiştirmelerinin ve enkesit burulmasının önlendiği noktalar arasındaki uzaklık, $L_{b}$ 'ye göre değişimlerini gösteren abaklar hazırlanıp yapısal tasarım mühendislerinin hizmetine sunulmuştur. Bu abaklar sayesinde el hesapları ve bilgisayar yazılımlarına ihtiyaç duyulmadan hızlı ve etkin bir şekilde eğilme elemanlarının boyutlandırılması sağlanmış olacaktır.

\section{EĞILME MOMENTINE MARUZ KALAN CELIK ELEMANLARIN TASIMA KAPASITELERINIIN BELIRLENMESI}

Eğilme momenti altında kiriş elemanların boyutlandırılmasını genellikle kiriş açıklığı boyunca en yüksek izin verilen eğilme momenti gerilmesi ve izin verilen düşey deplasman miktarı belirler. Kesme kuvvetinin kesit boyutlandırılmasına etkisi sadece kısa açıklıklı kirişlerde ve ağır yüklemelere maruz kalan kirişlerde hakimdir [15]. Bu çalışma sadece eğilme momenti göz önüne alınarak kiriş elemanların taşıma kapasitesini belirlemektedir. Nihai boyutlandırma için ÇYTHYE-2018'de [8] tanımlanan kesme kuvveti tasarım kriterleri ve düşey deplasman kriterleri birlikte göz önüne alınmalidir.

Güçlü eksenleri etrafında eğilme momentine maruz kalan I-enkesitli eğilme elemanlarının boyutlandırılmasını akma, lokal burkulma ve yanal burulmalı burkulma sınır durumları belirler. 
Eğilme momenti altında kiriş elemanının taşıyabileceği en yüksek karakteristik eğilme momenti dayanımı plastik eğilme momentine eşittir ve aşağıda tanımlanan Denklem (1) ile hesaplanır.

$M_{n}=M_{p}=F_{y} W_{p x}$

Burada, $M_{n}$ karakteristik eğilme momenti dayanımı, $M_{p}$ plastik eğilme momenti, $F_{y}$ yapısal çelik karakteristik akma gerilmesi ve $W_{p x} \mathrm{x}$-ekseni etrafinda plastik mukavemet momentidir.

Güçlü eksenleri etrafinda eğilme momentine maruz kalan I-enkesitli eğilme elemanlarının lokal burkulma sınır durumlarını belirleyebilmek için öncelikli olarak kesit sınıflandırılması yapılır. ÇYTHYE-2018 [8] eğilme elemanlarını enkesit parçalarının genişlik/kalınlık oranlarına göre kompakt, kompakt olmayan ve narin enkesit olarak üç gruba ayırır. Kesit sınıflandırılması hadde I-enkesitli eğilme elemanlarının başlık ve gövde enkesit parçaları için ayrı ayrı yapılır.

\section{A. ENKESITT PARÇALARININ SINIFLANDIRILMASI}

Eğilme momentine maruz kalan kiriş elemanların kesit sınıflandırılması enkesiti oluşturan her bir enkesit parçasının genişlik/kalınlık oranına, akma dayanımlarına ve elastisite modülüne bağlıdır.

Bu çalışma kapsamında incelenen I-enkesitli profillerin enkesit görünüşleri ve ebatlarına karşıllık gelen sembolleri Şekil 1'de gösterilmiştir.

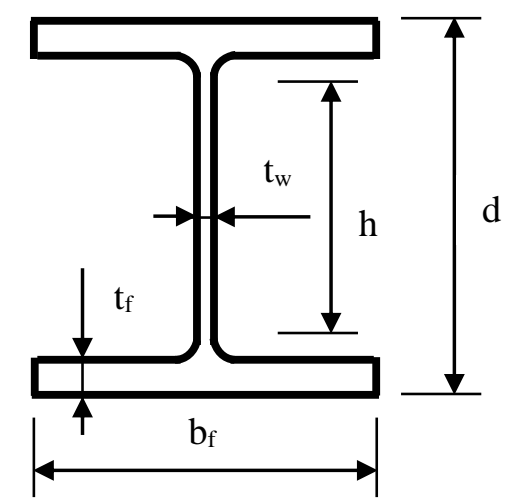

Şekil 1.I-enkesitli profillerin enkesit görünüşleri

\section{A. 1. Kompakt Enkesitler}

Başlık enkesit parçası için:

$\lambda_{f}=\frac{b_{f}}{2 t_{f}} \leq \lambda_{p f}=0.38 \sqrt{\frac{E}{F_{y}}}$

Gövde enkesit parçasiiçin:

$\lambda_{w}=\frac{h}{t_{w}} \leq \lambda_{p w}=3.76 \sqrt{\frac{E}{F_{y}}}$

Yukarıdaki koşulları karşılan enkesitler kompakt enkesitler olarak isimlendirilir. Kompakt enkesitlerde, lokal burkulma göçmeleri kiriş elemanının plastik moment kapasitesini aştıktan sonraki bölgede (plastik bölgede) gerçekleşir. 


\section{A. 2. Kompakt Olmayan Enkesitler}

Başlık enkesit parçası için:

$\lambda_{p f}=0.38 \sqrt{\frac{E}{F_{y}}}<\lambda_{f}=\frac{b_{f}}{2 t_{f}} \leq \lambda_{r f}=1.00 \sqrt{\frac{E}{F_{y}}}$

Gövde enkesit parçası için:

$\lambda_{p w}=3.76 \sqrt{\frac{E}{F_{y}}}<\lambda_{w}=\frac{h}{t_{w}} \leq \lambda_{r w}=5.70 \sqrt{\frac{E}{F_{y}}}$

Yukarıdaki koşulları karşılan enkesitlerkompakt olmayan enkesitler olarak isimlendirilir. Kompakt olmayan enkesitlerde, lokal burkulma göçmeleri kiriş elemanının elastik ve plastik moment kapasitesi arasındaki bölgede (elastik olmayan bölgede) gerçekleşir.

\section{A. 3. Narin Kesitler}

Başlık enkesit parçası için:

$\lambda_{f}=\frac{b_{f}}{2 t_{f}}>\lambda_{r f}=1.00 \sqrt{\frac{E}{F_{y}}}$

Gövde enkesit parçası için:

$\lambda_{w}=\frac{h}{t_{w}}>\lambda_{r w}=5.70 \sqrt{\frac{E}{F_{y}}}$

Yukarıdaki koşulları karşılan enkesitler narinenkesitler olarak isimlendirilir. Narinenkesitlerde, lokal burkulma göçmeleri kiriş elemanının elastik moment kapasitesine ulaşmadan önceki bölgede (elastik bölgede) gerçekleşir.

Burada, $E$ yapısal çelik elastisite modülü (200 GPa), $b_{f}$ ve $t_{f}$ Şekil 1'de gösterildiği gibi enkesit başlık parçasının sırasıyla genişliği ve kalınlığı, $h$ ve $t_{w}$ enkesit gövde parçasının sırasıyla yüksekliği ve kalınlığıdır. $\lambda_{f}$ başlık enkesit parçası için genişlik/kalınlık oranı, $\lambda_{p f}$ ve $\lambda_{r f}$ başlık enkesit parçası için ve $\lambda_{p w}$ ve $\lambda_{r w}$ gövde enkesit parçası için sırasıyla kompakt ve kompakt olmayan narinlik sınırlarıdır.

\section{B. TASARIM EĞİLME MOMENTİ DAYANIMI}

S275 malzeme sinıfindan teşkil edilen HEA260, HEA280, HEA300 profillerinin ve S355 malzeme sinıfindan teşkil edilen HEA180, HEA200, HEA220, HEA240, HEA260, HEA280, HEA300, HEA320, HEA340 profillerinin başlıkları kompakt olmayan enkesit sınıfina girerken bu çalışma kapsamında incelenecek diğer tüm HEA, HEB, IPE ve IPN profilleri kompakt enkesit sinıfına girmektedir. Güçlü eksenleri etrafında eğilme momentine maruz kalan, kompakt gövde ve kompakt olmayan başlık enkesit parçalarına sahip hadde I-enkesitli profillerin lokal burkulma sınır durumları aşağıda gösterilen Denklem (8) ile hesaplanır.

$M_{n}=M_{p}-\left(M_{p}-M_{r}\right)\left(\frac{\lambda_{f}-\lambda_{p f}}{\lambda_{r f}-\lambda_{p f}}\right)$

Burada, $W_{e x} \mathrm{x}$-ekseni etrafında elastik mukavemet momenti, $M_{r}$ değeri ilk akmanın başladığı andaki elastik eğilme momenti kapasitesidir ve aşağıdaki formül kullanılarak elde edilir. 
$M_{r}=0.7 F_{y} W_{e x}$

ÇYTHYE-2018 [8] I-enkesitli profillerin başlık enkesit parçalarındaki en yüksek basınç artık gerilme değerini akma dayanımının \%30 olarak kabul eder. Dolayısıyla eğilme momenti altındaki ilk akmalar yapısal çelik malzemenin akma dayanımının \%70'ine ulaştığı anda meydana gelir ve böylelikle $M_{r}$ değeri $0.70 F_{y} W_{e x}$ formülü ile hesaplanır.

Güçlü eksenleri etrafında eğilme momentine maruz kalan hadde I-enkesitli profillerin karakteristik eğilme momenti dayanımları basınç başlığında yanal yerdeğiştirmelerinin ve enkesit burulmasının önlendiği noktalar arasındaki uzaklık, $L_{b}$ değeri arttıkça plastik eğilme momenti değerine ulaşamadan yanal burulmalı burkulma göçmesi nedeni ile taşıma kapasitesini kaybedebilirler. Aşağıda verilen denklemler ve Şekil 2 güçlü eksenleri etrafında hadde I-enkesitli profillerin yanal burulmalı burkulma sınır durumlarının $L_{b}$ 'ye göre nasıl hesaplanmasını gerektiğini göstermektedir.

a. Eğer $L_{b} \leq L_{p}$ ise yanal burulmalı burkulma göçmesi meydana gelmez ve $M_{n}$ değeri $M_{p}$ değerine ulaşır.

b. Eğer $L_{p}<L_{b} \leq L_{r}$ ise

$M_{n}=C_{b}\left[M_{p}-\left(M_{p}-0.7 F_{y} W_{e x}\right)\left(\frac{L_{b}-L_{p}}{L_{r}-L_{p}}\right)\right] \leq M_{p}$

c. Eğer $L_{b}>L_{r}$ ise

$M_{n}=\left[\frac{C_{b} \pi^{2} E}{\left(\frac{L_{b}}{i_{t s}}\right)^{2}} \sqrt{1+0.078 \frac{J c}{W_{e x} h_{0}}\left(\frac{L_{b}}{i_{t s}}\right)^{2}}\right] W_{e x} \leq M_{p}$

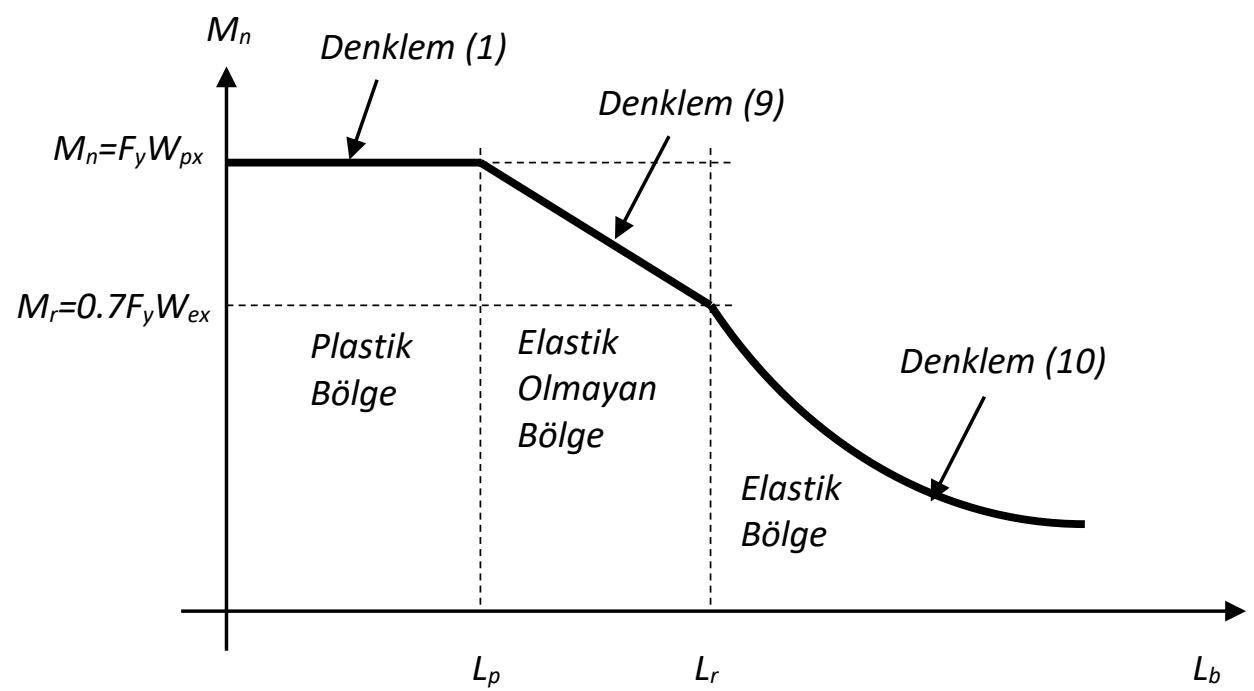

Şekil2. Güçlü eksenleri etrafinda eğilme momentine maruz kalan hadde I-enkesitli profillerin eğilme momenti taşıma kapasitelerinin $L_{b}$ 'ye göre değişimi $\left(C_{b}=1\right)$ [13].

Burada, $L_{p}$ ve $L_{r}$ sirasiyla akma sinır durumu ve elastik olmayan yanal burulmalı burkulma sinır durumu için sınır uzunluklardır ve Denklem 12 ve Denklem 13 kullanılarak hesaplanır. $C_{b}$ moment düzeltme katsayısıdır ve Denklem 15 kullanılarak hesaplanır. Ayrıca $h_{o}$ enkesit başlıklarının ağırlık 
merkezleri arasındaki uzaklık, $J$ burulma sabiti, $c$ çift simetri eksenli I-enkesitlerde 1.0'a eşit bir katsayı ve $i_{t s}$ ise etkinatalet yarıçapıdır ve Denklem 14 kullanılarak hesaplanır.

$$
\begin{aligned}
L_{p} & =1.76 i_{y} \sqrt{\frac{E}{F_{y}}} \\
L_{r} & =1.95 i_{t s} \frac{E}{0.7 F_{y}} \sqrt{\frac{J c}{W_{e x} h_{0}}+\sqrt{\left(\frac{J c}{W_{e x} h_{0}}\right)^{2}+6.76\left(\frac{0.7 F_{y}}{E}\right)^{2}}} \\
i_{t s} & =\sqrt{\frac{\sqrt{I_{y} C_{w}}}{W_{\text {ex }}}} \\
C_{b} & =\frac{12.5 M_{\text {maks }}}{2.5 M_{\text {maks }}+3 M_{A}+4 M_{B}+3 M_{C}}
\end{aligned}
$$

Burada, $C_{w}$ çarpılma sabiti, $M_{\text {maks }}, M_{A}, M_{B}$ ve $M_{C}$ yanal stabilite bağlantısı ile desteklenen noktalar arasındaki kiriş uzunluğu boyunca sırasıyla en büyük, kiriş uzunluğunun $1 / 4,1 / 2$ ve $3 / 4$ noktasındaki eğilme momentlerinin mutlak değerleridir.

Tasarım eğilme momenti dayanımları karakteristik dayanımın 0.9 ile çarpılması ile ve güvenli eğilme momenti dayanımları ise karakteristik dayanımın 1.67'ye bölünmesi ile elde edilir.

$C_{b}$ değeri yanal mesnetler arasında kiriş açılığı boyunca moment değişiminin eğilme momenti taşıma kapasitesine etkisini göz önüne alan katsayıdır. $C_{b}$ değeri arttıkça yanal burulmalı burkulma dayanıma dayanan eğilme momenti taşıma kapasitesi de artar. Yanal burulmalı burkulma dayanımı açısından en olumsuz durum eğilme momentinin yanal mesnetler arasında sabit olduğu durumdur. Bu durumda, eğilme momentine maruz kalan kiriş elemanı yanal mesnetler arasındaki tüm uzunluk boyunca en yüksek eğilme momentine ve dolayısıyla enkesitin basınç başlığı ise yanal mesnetler arasındaki tüm uzunluk boyunca en yüksek basınç gerilmesine maruz kalacaktır. Eğer yanal mesnetler boyunca bir moment değişimi mevcutsa basınç başlı̆̆ının sadece bir noktasında en yüksek basınç gerilmesi meydana gelir ve bu noktanın dışındaki diğer tüm bölgelerde basınç gerilmesi düşer. Başlık elemanındaki daha düşük basınç gerilmesi yanal burulmalı burkulma dayanımını arttırır [16]. $\mathrm{Bu}$ çalışmada en kritik eğilme momenti taşıma kapasitesi belirlendiği için eğilme momentinin yanal mesnetler arasında sabit olduğu kabul edilerek $C_{b}$ değeri 1.0 olarak göz önüne almıştır.

Yukarıda tanımlanan tüm denklemler göz önüne alınarak S235, S275 ve S355 malzeme sınıflarından teşkil edilmiş HEA profillerinin ÇYTHYE-2018'de [8] tanımlanan YDKT esaslarına göre güçlü eksen etrafındaki tasarım eğilme momentinin $L_{b}$ 'ye göre değişimleri sırasıyla Şekil 3, Şekil 4 ve Şekil 5'de, HEB profillerinin Şekil 6, Şekil 7 ve Şekil 8'de, IPE profillerinin Şekil 9, Şekil 10 ve Şekil 11'de, IPN profillerinin ise Şekil 12, Şekil 13 ve Şekil 14'de verilmiştir. 

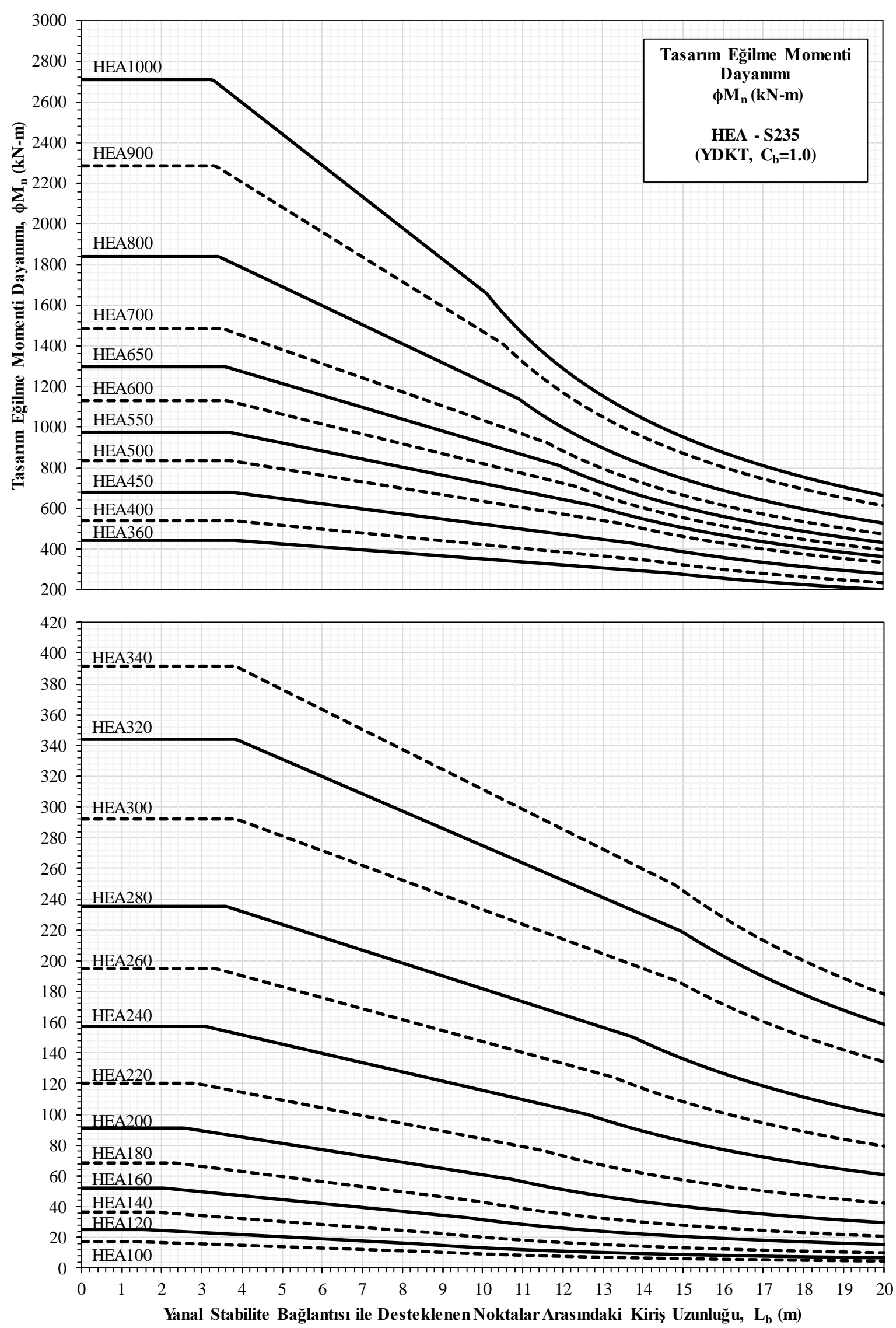

Şekil 3. S235 malzeme ve HEA enkesitlerine ait tasarım eğilme momenti dayanımlart 

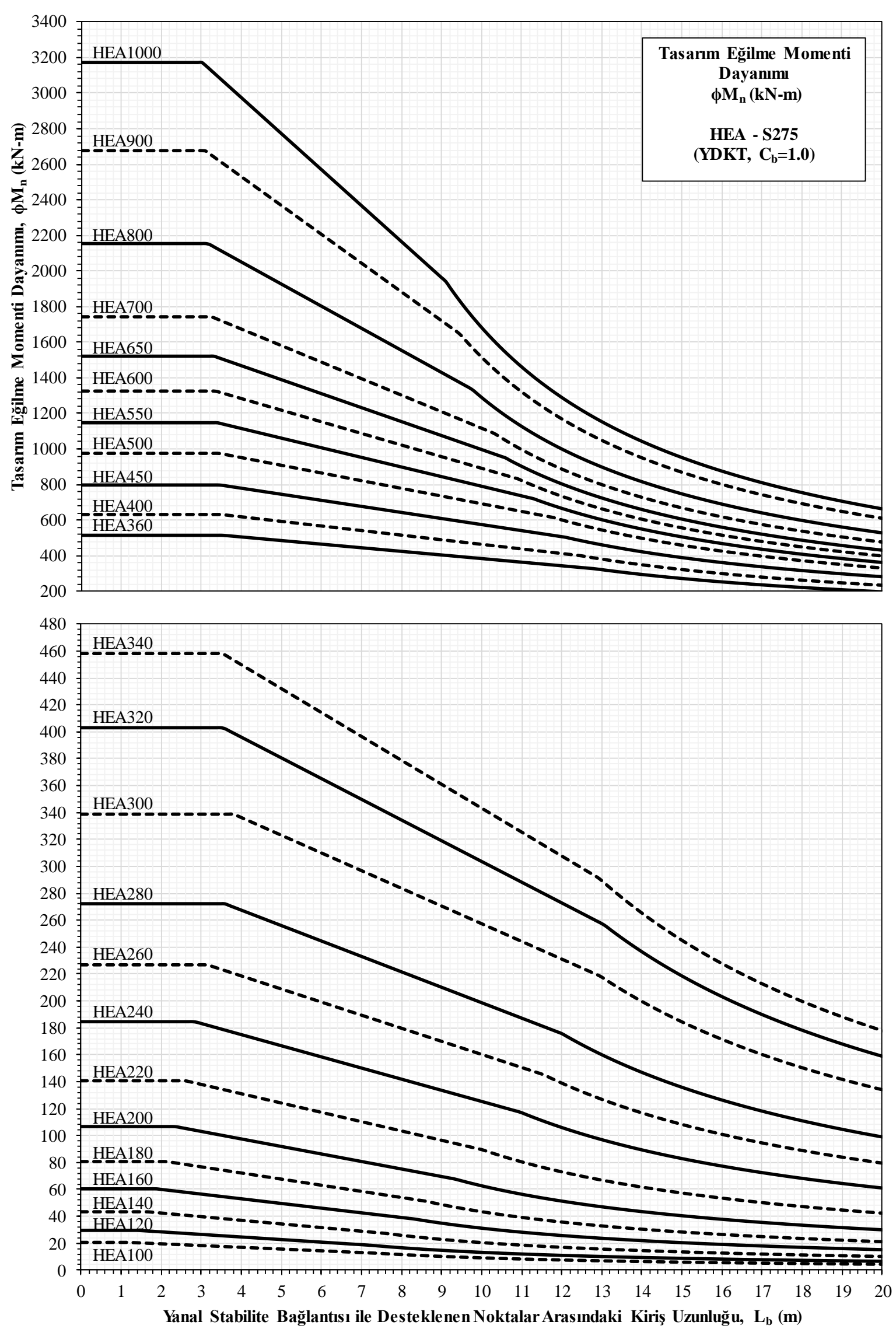

Şekil 4. S275 malzeme ve HEA enkesitlerine ait tasarım eğilme momenti dayanımlart 

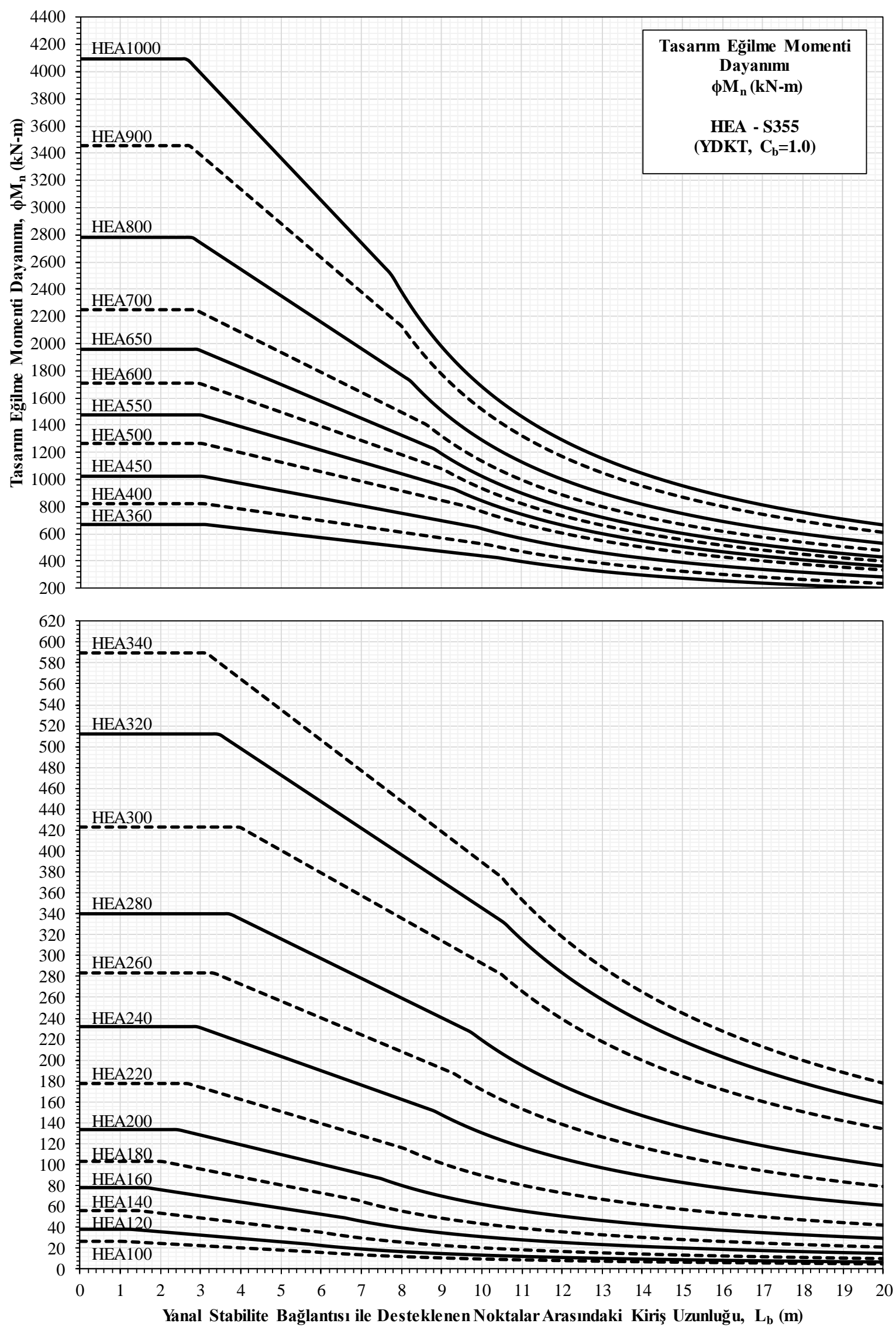

Şekil 5. S355 malzeme ve HEA enkesitlerine ait tasarım eğilme momenti dayanımlart 

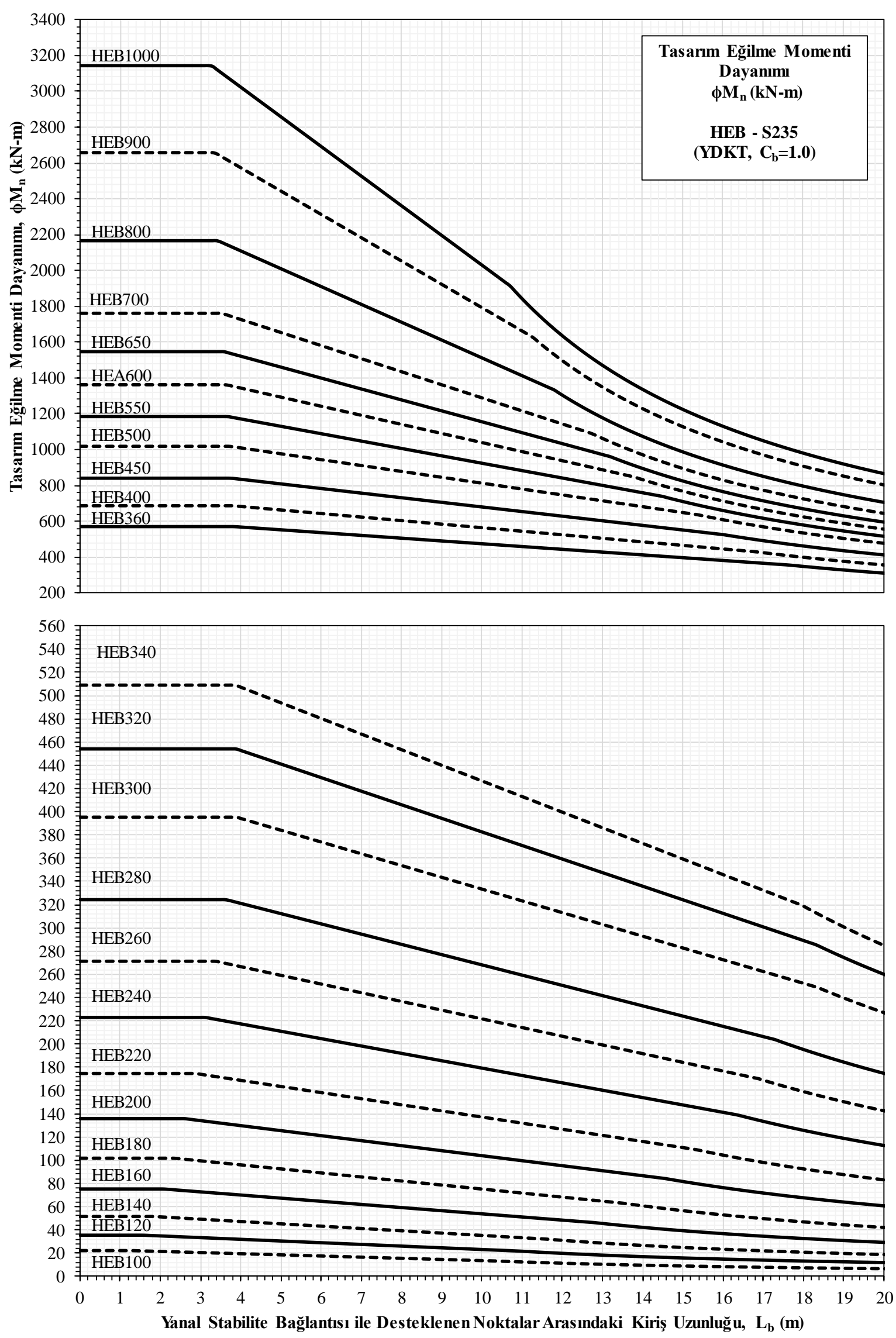

Şekil 6. S235 malzeme ve HEB enkesitlerine ait tasarım eğilme momenti dayanımları 

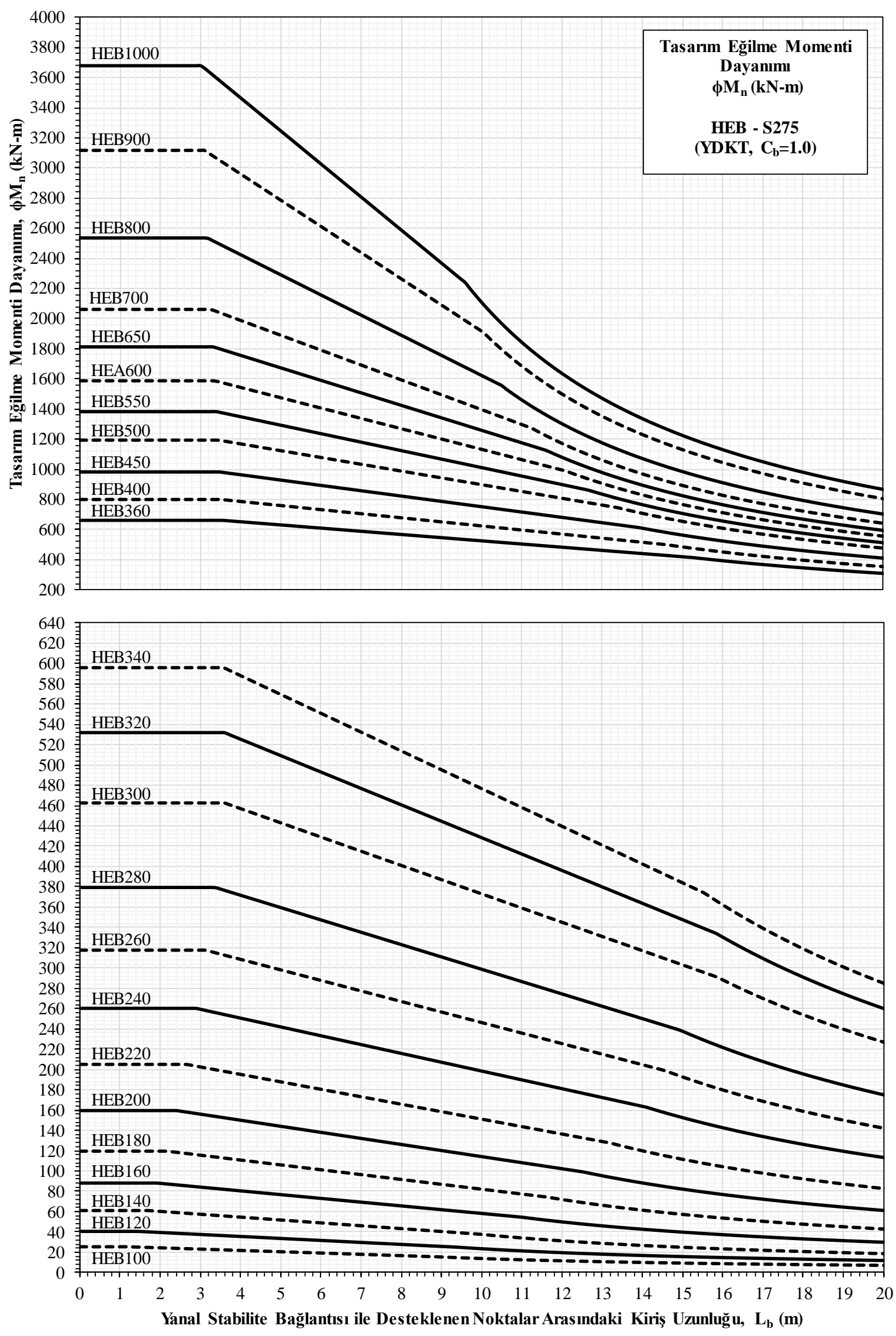

Şekil 7. S275 malzeme ve HEB enkesitlerine ait tasarım eğilme momenti dayanımları 

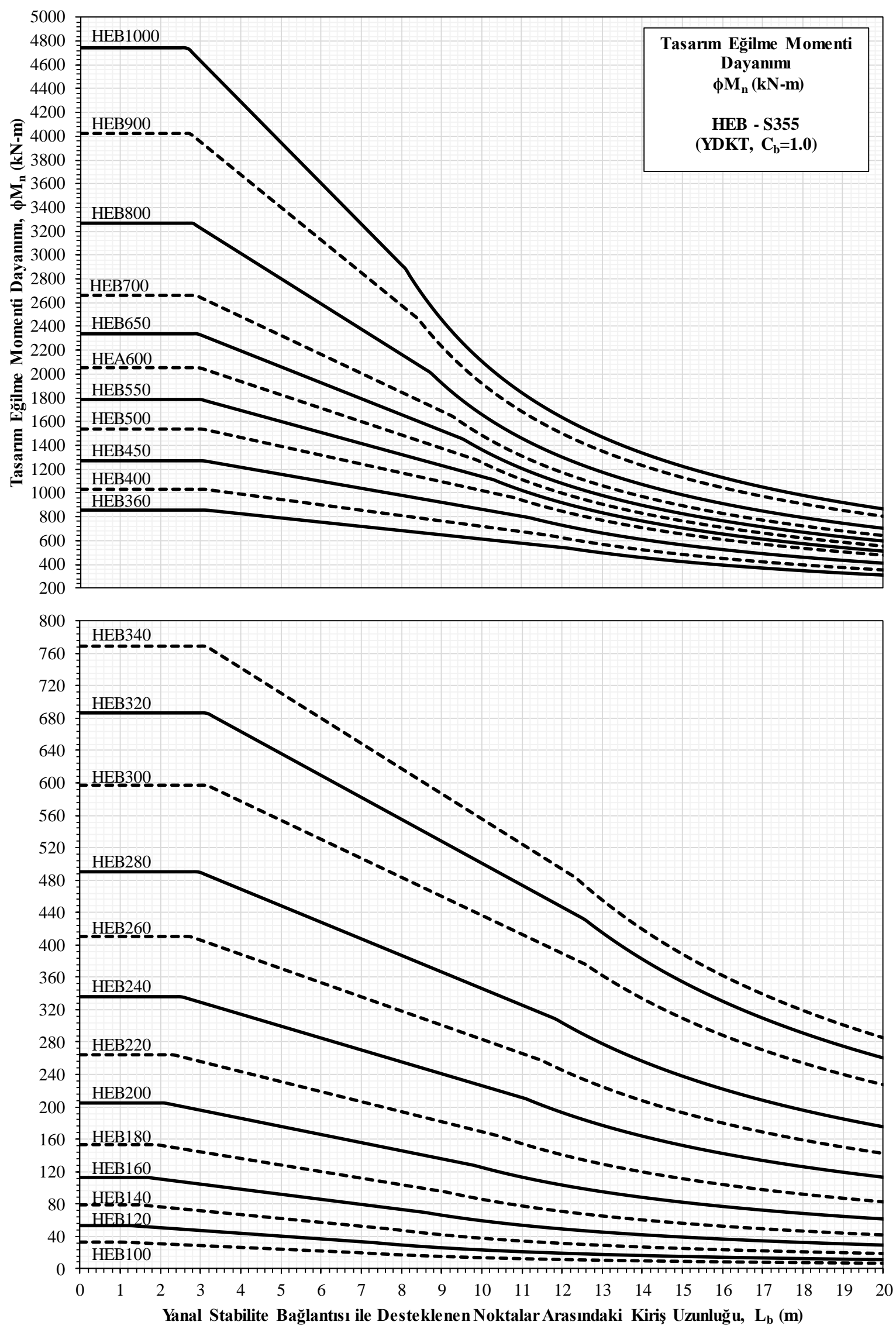

Şekil 8. S355 malzeme ve HEB enkesitlerine ait tasarım eğilme momenti dayanımlart 

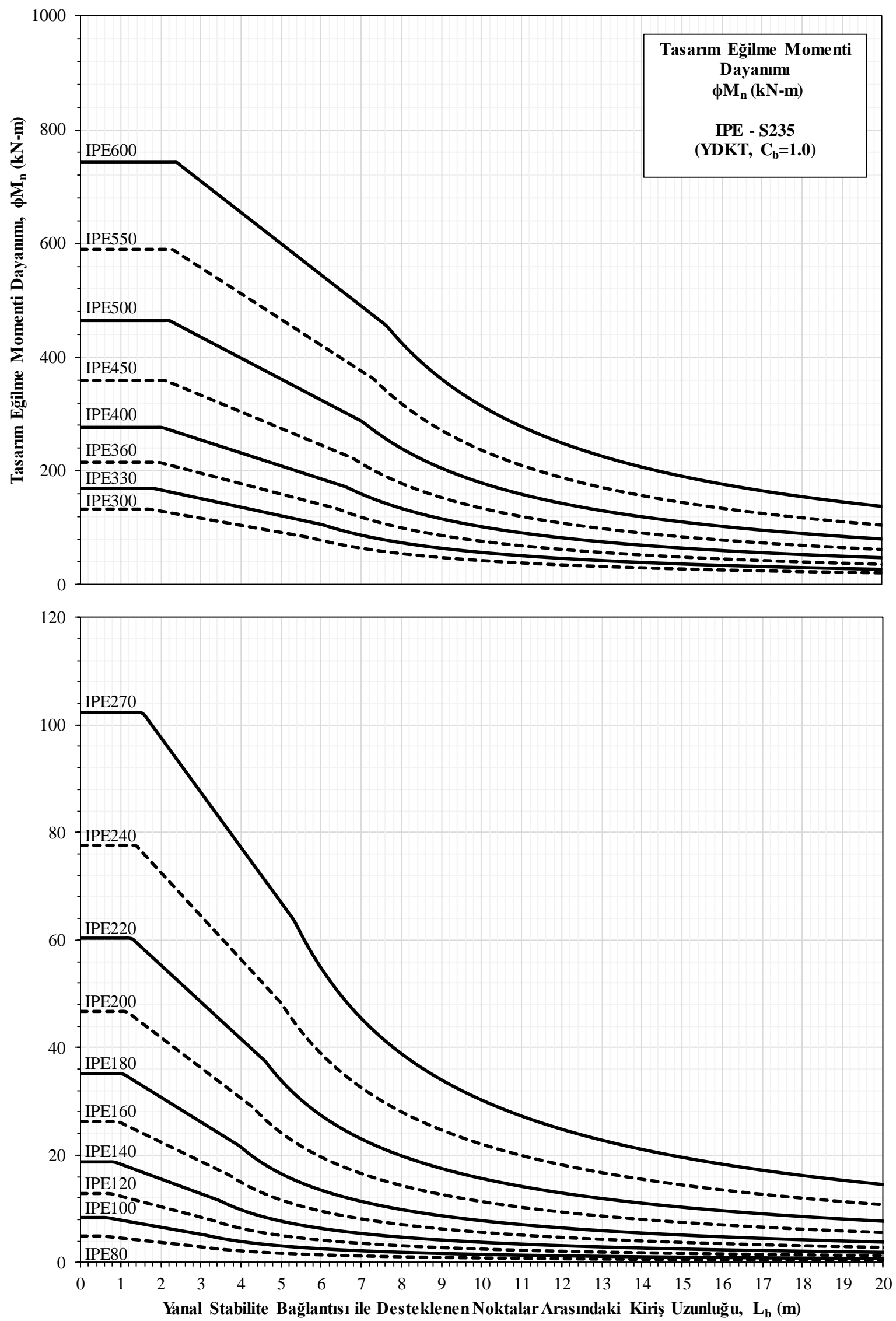

Şekil 9. S235 malzeme ve IPE enkesitlerine ait tasarım eğilme momenti dayanımları 

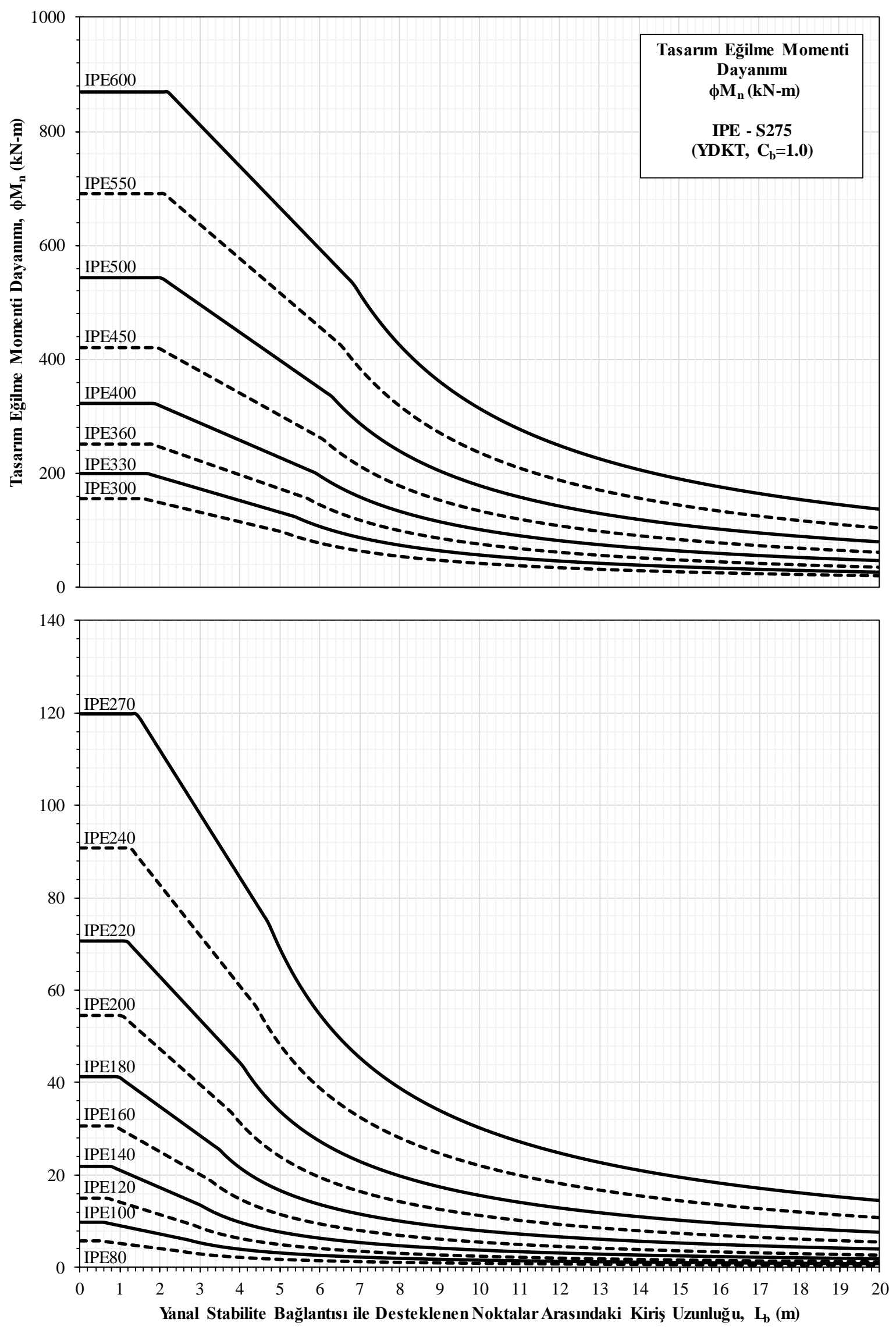

Şekil 10. S275 malzeme ve IPE enkesitlerine ait tasarım eğilme momenti dayanımlarl 

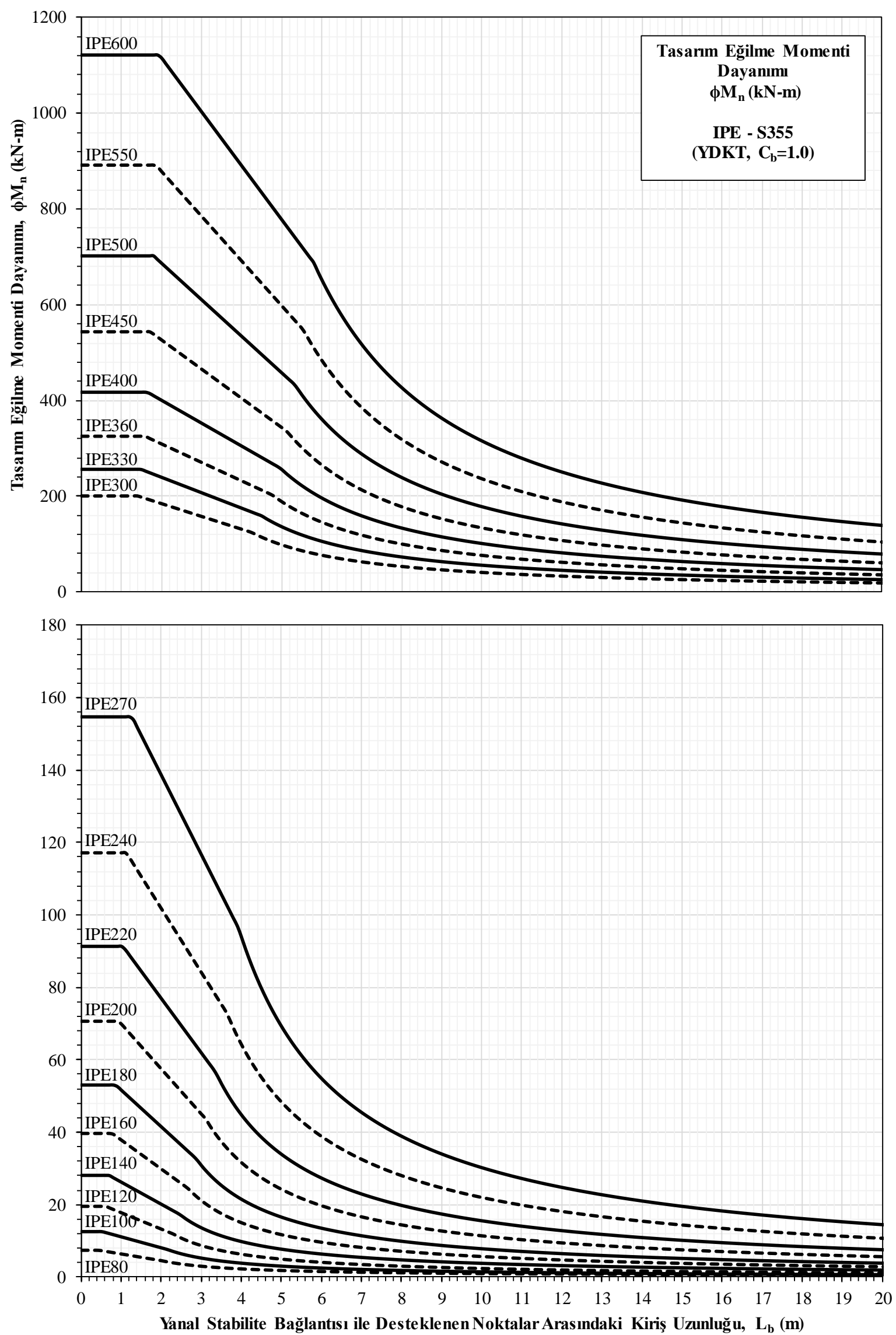

Şekil 11. S355 malzeme ve IPE enkesitlerine ait tasarım eğilme momenti dayanımları 

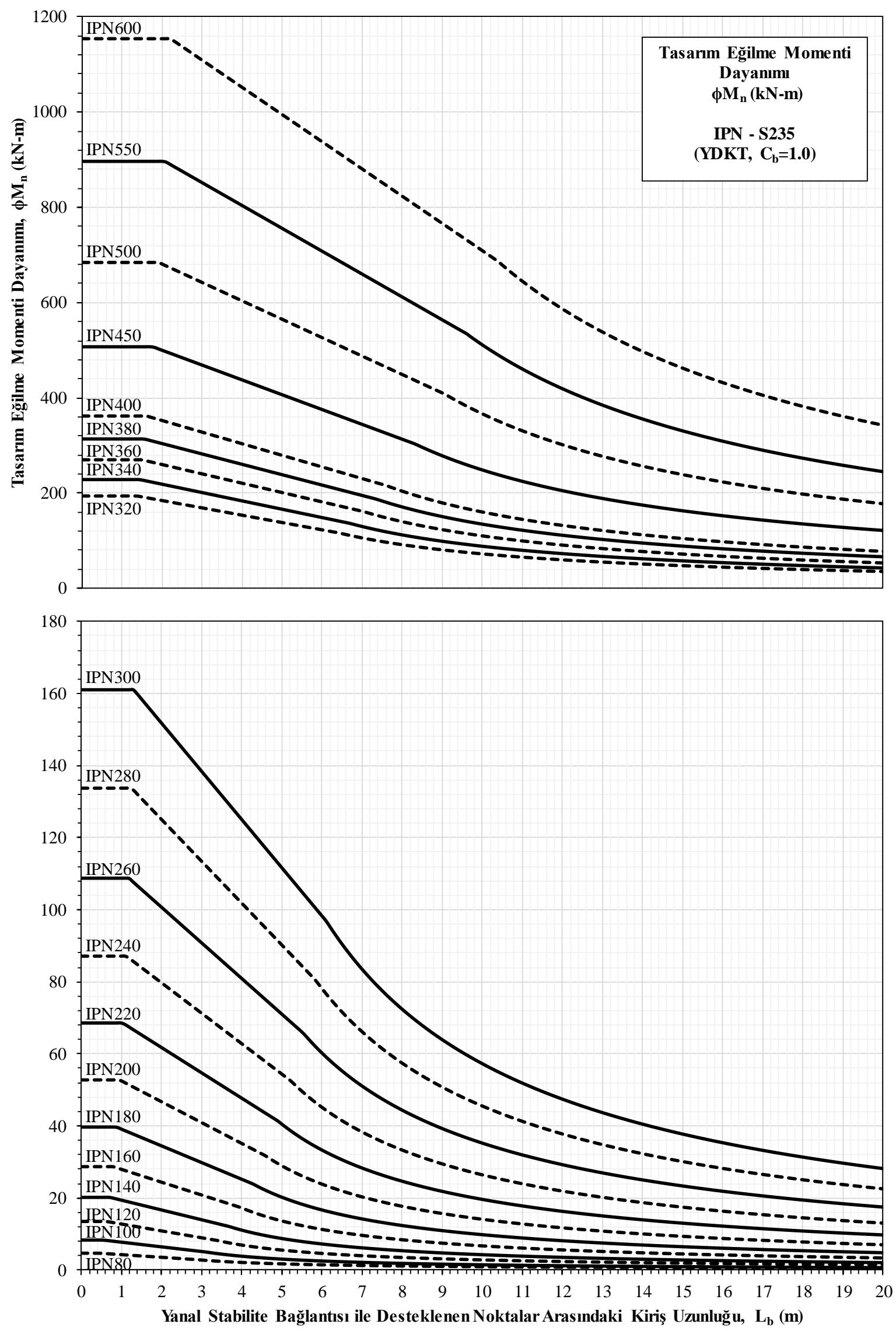

Şekil 12. S235 malzeme ve IPN enkesitlerine ait tasarım eğilme momenti dayanımlar 

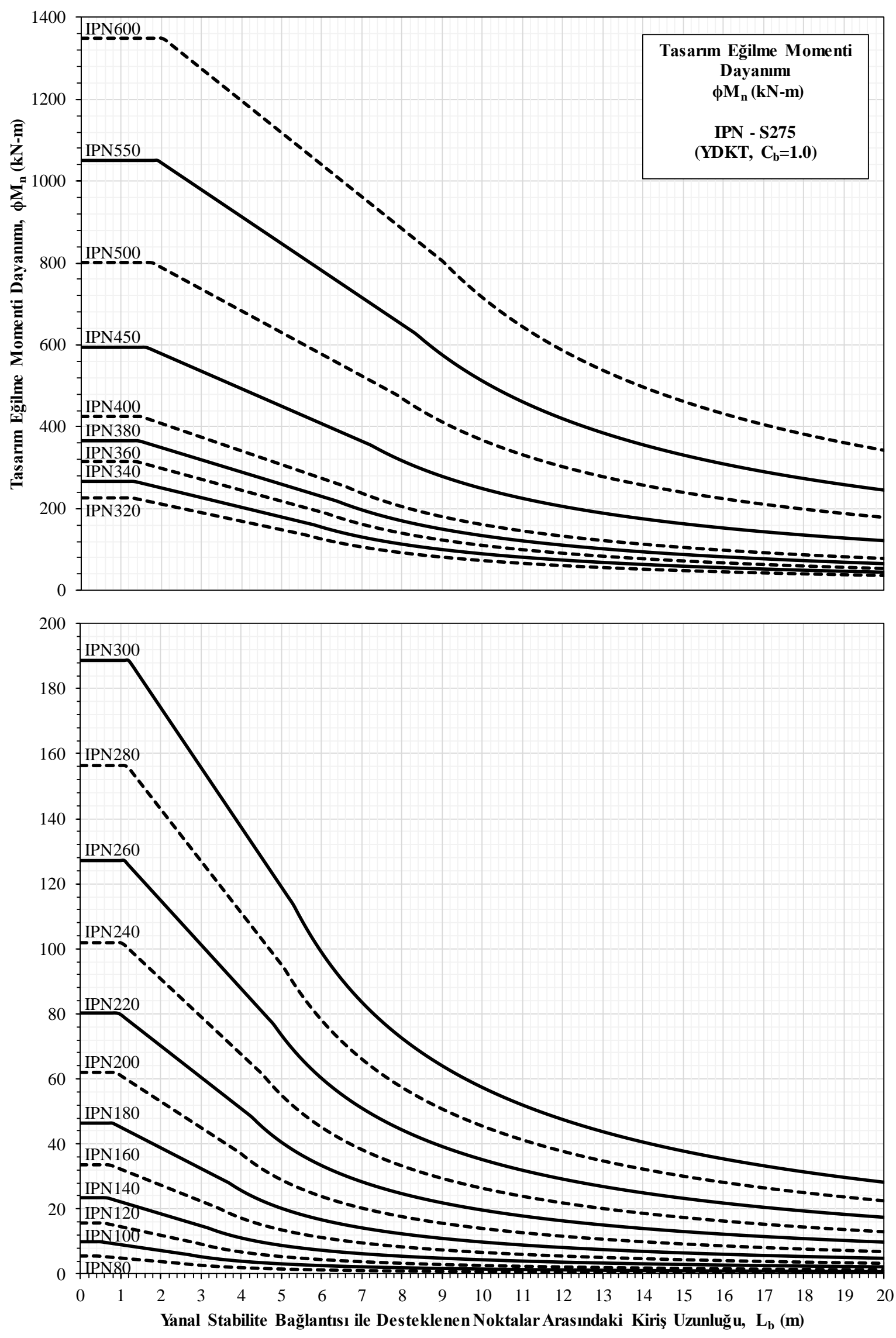

Şekil 13. S275 malzeme ve IPN enkesitlerine ait tasarım eğilme momenti dayanımlart 

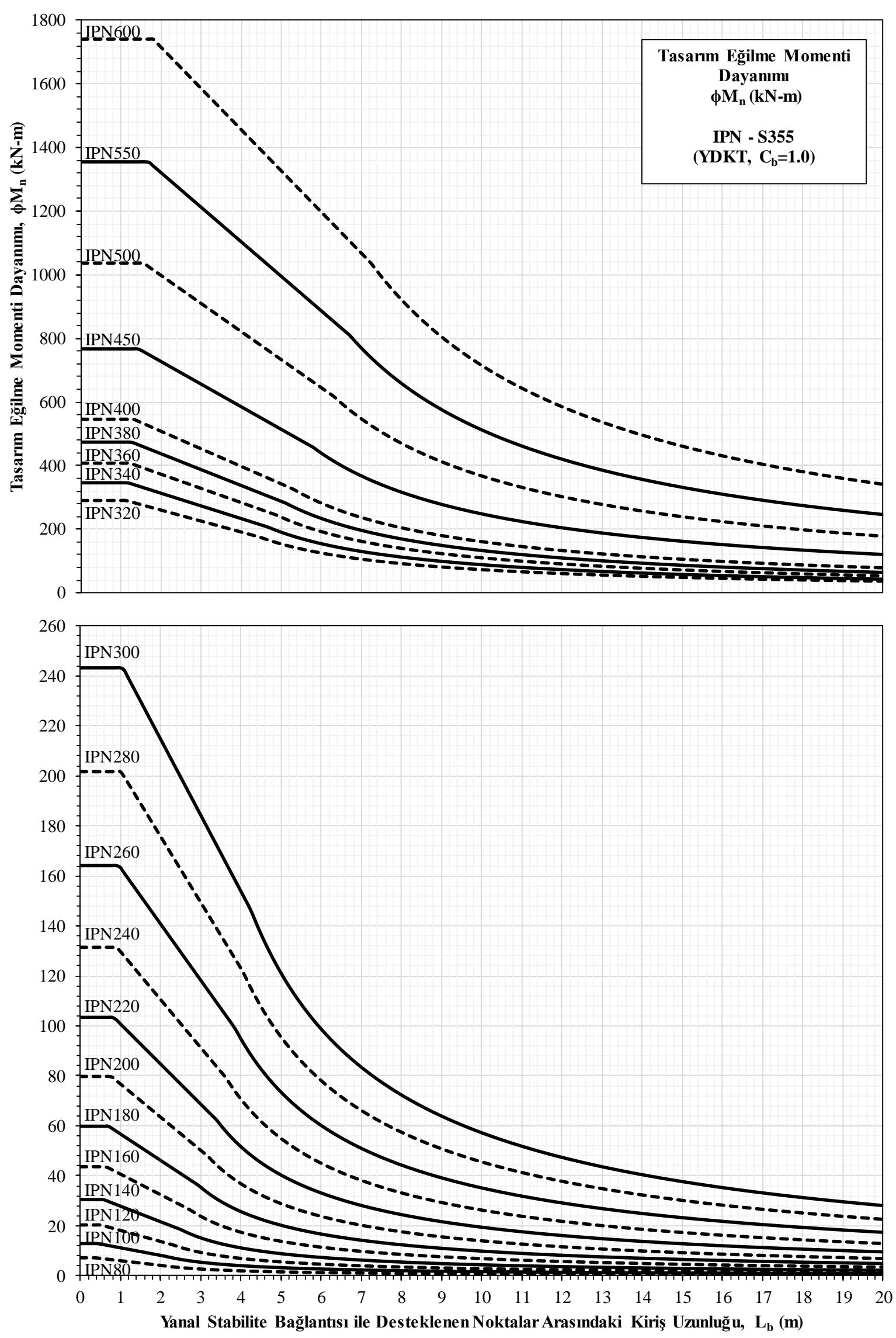

Şekil 14. S355 malzeme ve IPN enkesitlerine ait tasarım eğilme momenti dayanımları 


\section{SAYISAL UYGULAMA}

$\mathrm{Bu}$ bölümde, eğilme elemanları için sunulan abakların nasıl kullanıldığı ve bu abaklar kullanılarak elde edilen sonuçların ÇYTHYE-2018'de [8] tanımlanan ilgili formüller kullanılarak elde edilen sonuçlar ile karşılaştırması gerçekleştirilmiştir. Bu amaç için aşağıda tanımlanan farklı malzeme sinıflarına (S275 ve S355), farklı enkesitlere (HEA300 ve IPE500) ve farklı $L_{b}$ değerlerine (3000 ve $6000 \mathrm{~mm}$ )sahip iki ucu basit mesnetli (mafsallı) eğilme elemanlarının sabit eğilme momenti altında $\left(C_{b}=1\right)$ YDKT tasarım esaslarına göre tasarım eğilme momenti dayanımları iki farklı yönteme göre de belirlenmiş ve sonuçlar birbiri ile karşılaştırılmıştır.

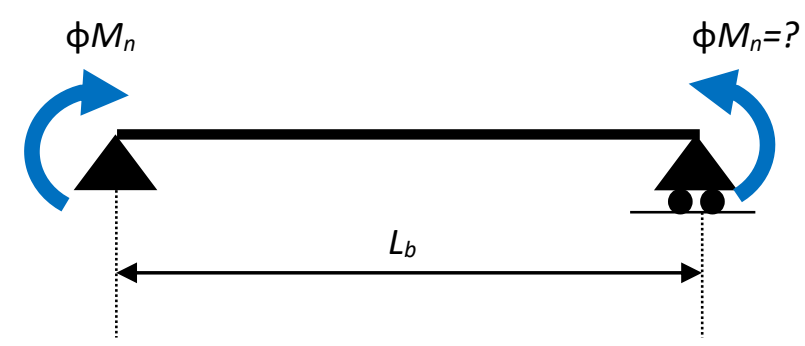

Şekil 15. Sayısal uygulama için kullanılan eğilme elemanı

\section{A. SAYISAL UYGULAMA 1}

Yanal mesnetler arası mesafesi $3000 \mathrm{~mm}$ olan ve uzunluğu boyunca sabit eğime momentine maruz kalan S275 malzeme sınıfından ve HEA300 profilinden teşkil edilen kiriş elemanının tasarım eğilme momenti dayanımını hesaplayınız.

\section{A. 1. ÇYTHYE-2018'de [8] Tanımlanan Formüllerin Kullanılması ile Tasarım Eğilme Momenti Dayanımının Belirlenmesi}

Eğilme momentine maruz kalan kiriş elemanının kompakt, kompakt olmayan veya narin enkesit sınıfına ait olduğunu belirleyebilmek için Denklem (2 7) kullanılarak kesit sınıflandırılması yapılır.

$$
\begin{aligned}
& \lambda_{f}=\frac{b_{f}}{2 t_{f}}=\frac{300}{2 \times 14}=10.7 \leq \lambda_{r}=0.38 \sqrt{\frac{E}{F_{y}}}=0.38 \sqrt{\frac{200000}{275}}=10.2 \text { Kompakt olmayan başlik } \\
& \lambda_{w}=\frac{h}{t_{w}}=\frac{208}{8.5}=24.5 \leq \lambda_{r}=3.76 \sqrt{\frac{E}{F_{y}}}=3.76 \sqrt{\frac{200000}{275}}=101.4 \text { Kompakt gövde }
\end{aligned}
$$

Kompakt olmayan enkesit parçasına sahip olduğu için eğilme momentine maruz kalan S275 malzeme sınıfından teşkil edilen HEA300 profilin başlık elemanında basınç yükü altında lokal burkulma gerçekleşebilir. Dolayısıyla tasarım eğilme momenti dayanımının tayininde Denklem (8)'de verilen lokal burkulma sınır durumu göz önüne alınmalıdır.

$M_{n 1}=M_{p}-\left(M_{p}-0.7 F_{y} W_{e x}\right)\left(\frac{\lambda_{f}-\lambda_{p f}}{\lambda_{r f}-\lambda_{p f}}\right)$

Lokal burkulma sınır durumunun belirlenmesi için öncelikli olarak plastik eğilme momenti dayanımı, $M_{p}$ ve elastik olmayan eğilme momenti dayanımı, $M_{r}$ değerlerinin belirlenmesi gerekmektedir.

$M_{p}=F_{y} W_{p x}=275 \times 1.383 \times 10^{6} \times 10^{-6}=380.3 \mathrm{kNm}$ 
$M_{r}=0.7 F_{y} W_{e x}=0.7 \times 275 \times 1.26 \times 10^{6} \times 10^{-6}=242.6 \mathrm{kNm}$

$M_{n 1}=380.3-(380.3-242.6)\left(\frac{10.7-10.2}{24.0-10.2}\right)=376.5 \mathrm{kNm}$

Eğilme elemanının yanal burulmalı burkulma tahkiki için öncelikli olarak plastik, $L_{p}$ sınır uzunluğu belirlenir.

$L_{p}=1.76 i_{y} \sqrt{\frac{E}{F_{y}}}=1.76 \times 74.9 \times \sqrt{\frac{200000}{275}}=3555 \mathrm{~mm}$

$L_{b}=3000 \mathrm{~mm} \leq L_{p}=3555 \mathrm{mmolduğu} \mathrm{için} \mathrm{yanal} \mathrm{burulmalı} \mathrm{burkulma} \mathrm{gerçekleşmez.} \mathrm{Dolayısıyla} \mathrm{tasarım}$ eğilme momenti kapasitesi,

$\phi M_{n}=0.9 \times M_{n 1}=338.8 \mathrm{kNm}$

\section{A. 2. Önerilen Abakların Kullanılması ile Tasarım Eğilme Dayanımının Belirlenmesi}
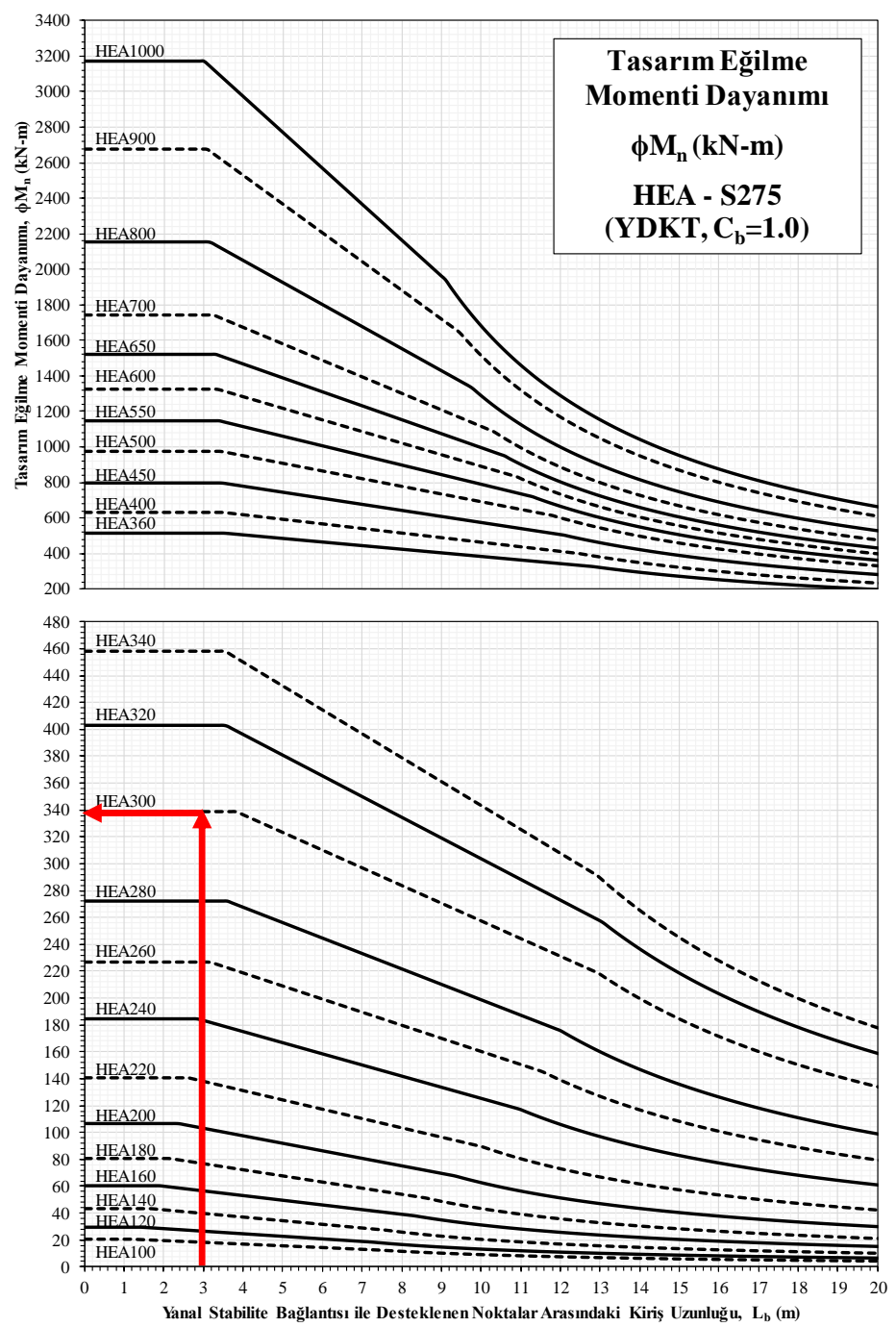

Şekil 16. Sayısal uygulama için kullanılan abak 
Şekil 4'de verilen abak kullanılarak $L_{b}=3000 \mathrm{~mm}$ değeri içinS275 malzeme sınfından teşkil edilen HEA300 profilinin tasarım eğilme momenti dayanımı $\phi M_{n}=340 \mathrm{kNm}$ değeri okunur.ÇYTHYE2018 'de [8] tanımlanan formüller ile elde edilen değer arasındaki fark \%0.3 olarak hesaplanır.

\section{B. SAYISAL UYGULAMA 2}

Yanal mesnetler arası mesafesi $6000 \mathrm{~mm}$ olan ve uzunluğu boyunca sabit eğime momentine maruz kalan S355 malzeme sınıfından ve IPE300 profilinden teşkil edilen kiriş elemanının tasarım eğilme momenti dayanımını hesaplayınız.

\section{B. 1. ÇYTHYE-2018'de [8] Tanımlanan Formüllerin Kullanılması ile Tasarım Eğilme Momenti Dayanımının Belirlenmesi}

Eğilme momentine maruz kalan kiriş elemanının kompakt, kompakt olmayan veya narin enkesit sınıfına ait olduğunu belirleyebilmek için Denklem (2 7) kullanılarak kesit sınıflandırılması yapılır.

$$
\begin{array}{ll}
\lambda_{f}=\frac{b_{f}}{2 t_{f}}=\frac{200}{2 \times 16}=6.3 \leq \lambda_{r}=0.38 \sqrt{\frac{E}{F_{y}}}=0.38 \sqrt{\frac{200000}{355}}=9.0 \quad \text { Kompakt başlik } \\
\lambda=\frac{h}{t_{w}}=\frac{426}{10.2}=41.8 \leq \lambda_{r}=3.76 \sqrt{\frac{E}{F_{y}}}=3.76 \sqrt{\frac{200000}{355}}=89.2 \quad \text { Kompakt gövde }
\end{array}
$$

Eğilme momentine maruz kalan S355 malzeme sınıfından teşkil edilen IPE500 profili kompakt olduğu için eğilme momenti altında lokal burkulma oluşması beklenmez. Dolayısıyla tasarım eğilme momenti dayanımının tayininde Denklem (8)'de verilen lokal burkulma sınır durumu göz önüne alınmayacaktır.

Eğilme elemanının yanal burulmalı burkulma tahkiki için öncelikli olarak plastik, $L_{p}$ ve elastik olmayan, $L_{r}$ sinır uzunlukları belirlenir.

$$
\begin{aligned}
& L_{p}=1.76 i_{y} \sqrt{\frac{E}{F_{y}}}=1.76 \times 43.1 \times \sqrt{\frac{200000}{355}}=1801 \mathrm{~mm} \\
& i_{t s}=\sqrt{\frac{\sqrt{I_{y} C_{w}}}{W_{e x}}}=\sqrt{\frac{\sqrt{2.142 \times 10^{7} \times 1.249 \times 10^{12}}}{1.928 \times 10^{6}}}=51.8 \mathrm{~mm} \\
& L_{r}=1.95 i_{t s} \frac{E}{0.7 F_{y}} \sqrt{\frac{J c}{W_{e x} h_{0}}+\sqrt{\left(\frac{J c}{W_{e x} h_{0}}\right)^{2}+6.76\left(\frac{0.7 F_{y}}{E}\right)^{2}}}=5347 \mathrm{~mm}
\end{aligned}
$$

$L_{b}=6000 \mathrm{~mm} \geq L_{r}=5347 \mathrm{~mm}$ olduğu için eğilme elemanın eğilme momenti sınır durumunu elastik yanal burulmalı burkulma dayanımı belirleyecektir.

$M_{n}=\left[\frac{C_{b} \pi^{2} E}{\left(\frac{L_{b}}{i_{t s}}\right)^{2}} \sqrt{1+0.078 \frac{J c}{W_{e x} h_{0}}\left(\frac{L_{b}}{i_{t s}}\right)^{2}}\right] W_{e x} \leq M_{p}$ 
$M_{p}=F_{y} W_{p x}=355 \times 2.194 \times 10^{6} \times 10^{-6}=778.9 \mathrm{kNm}$

$M_{n}=\left[\frac{1.0 \pi^{2} 200000}{\left(\frac{6000}{51.8}\right)^{2}} \sqrt{1+0.078 \frac{8.929 \times 10^{5} \times 1}{1.928 \times 10^{6} \times 484}\left(\frac{6000}{51.8}\right)^{2}}\right] 1.928 \times 10^{6} \leq M_{p}$

$M_{n}=401.3 \leq 778.9 \mathrm{kNm}$

Tasarım eğilme momenti kapasitesi,

$\phi M_{n}=0.9 \times M_{n}=361.1 \mathrm{kNm}$

B. 2. Önerilen Abakların Kullanılması ile Tasarım Eğilme Dayanımının Belirlenmesi

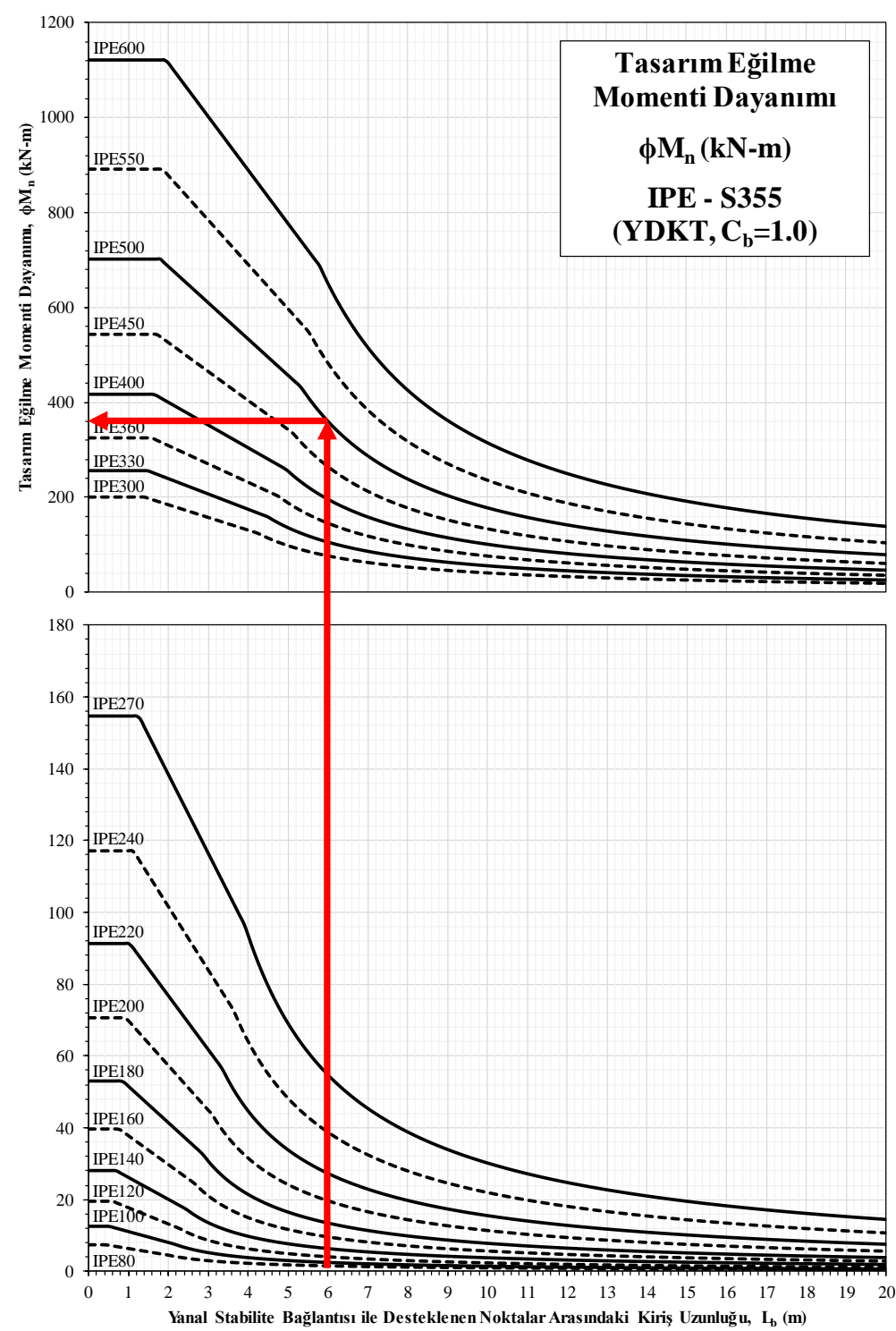

Şekil 17. Saylsal uygulama için kullanılan abak 
Şekil 11'de verilen abak kullanılarak $L_{b}=6000 \mathrm{~mm}$ değeri için S355 malzeme sınfindan teşkil edilen IPE500 profilinin tasarım eğilme momenti dayanımı $\phi M_{n}=360 \mathrm{kNm}$ değeri okunur. ÇYTHYE-2018'de [8] tanımlanan formüller ile elde edilen değer arasındaki fark \%0.3 olarak hesaplanır.

\section{IV.SONUC}

$\mathrm{Bu}$ çalıșma ÇYTHYE-2018'de [8] yönetmeliğine göre eğilme momentine maruz kalan kiriș elemanların boyutlandırılması için yardımcı abaklar sunmaktadır. Bu çalışma kapsamında göz önüne alınan kriterler ve yapılan kabuller aşağıda sıralanmıştır.

- S235, S275 ve S355 malzeme sinıfları kullanılmıştır.

- HEA, HEB, IPE ve IPN profillerinden teşkil edilmiştir.

- YDKT esasları kullanılmıştır.

- Eğilme I-enkesitli kiriş elemanın güçlü ekseninde etrafındadır.

- Yanal mesnetler arasinda moment sabittir $\left(C_{b}=1.0\right)$.

- Lokal burkulmalar ve yanal burulmalı burkulmalar göz önüne alınmıştır.

$\mathrm{Bu}$ abaklar sayesinde güçlü eksenleri etrafında eğilme momentine maruz kalan elemanların tasarım eğilme momenti dayanımları ÇYTHYE-2018'de [8] tanımlanan karmaşık formülleri kullanmaya gerek kalmadan belirlenebilecek ve böylece hılı ve etkin bir şekilde eğilme elemanları boyutlandırabileceklerdir. $\mathrm{Bu}$ çalışmada sunulan abaklar kullanılarak elde edilen tasarım eğilme momenti dayanımları ile ÇYTHYE-2018'de [8] tanımlanan formüller ile elde edilen dayanım değerleri iki farklı sayısal uygulama için hesaplanmış ve aralarındaki hata oranı $\% 0.3$ olarak rapor edilmiştir. $\mathrm{Bu}$ sonuçlar tasarım eğilme momenti dayanımlarının elde edilmesi için sunulan abakların çok kullanışlı ve güvenli olduğunu göstermektedir.

\section{KAYNAKLAR}

[1] Standard specification for structural steel for building, American Institute of Steel Construction AISC, Chicago, 1923.

[2] Specification for the use of structural steel in building, British Standard Institution BS 449, London, 1932.

[3] Çelik yapıların hesap ve yapım kuralları, Türk Standartları Enstitüsü TS 648, Ankara, 1980.

[4] Specification for structural steel buildings, American Institute of Steel Construction ANSI/AISC 360-16, Chicago, 2016.

[5] Eurocode 3, Design of steel structures-part 1: general rules and rules for buildings, European Standard, Comit Européen de NormalisationEN 1993-1:2004, Brussels, 2004.

[6] Design of steel structures, National Standard of Canada, CSA S16:19, Ontorio, 2019. 
[7] Standard specifications for steel and composite structures, Japan Society of Civil Engineers, JSCE-2007, Tokyo, Japan, 2007.

[8] Çelik yapıların tasarım, hesap ve yapımına dair esaslar, Çevre ve Şehircilik Bakanlığı ÇYTHYE-2018, Ankara, 2018.

[9] Steel construction manual, American Institute of Steel Construction AISC, The Fifteenth Edition, Chicago, 2018.

[10] Steel building design: Design Data, The Steel Construction Institute, Berkshire, The British Construction Steelwork Association Ltd, London, 2011.

[11] Joints in steel construction: Simple Joints To Eurocode 3, The Steel Construction Institute, Berkshire, The British Construction Steelwork Association Ltd, London, 2014.

[12] Joints in steel construction: Moment-Resisting Joints To Eurocode 3, The Steel Construction Institute, Berkshire, The British Construction Steelwork Association Ltd, London, 2013.

[13] Çelik yapıların tasarım, hesap ve yapım esaslarına dair yönetmelik hakkında uygulama kılavuzu, Çevre ve Şehircilik Bakanlığı, Ankara, 2017.

[14] M. B. Bozkurt, "Basınç elemanları için yardımcı abaklar," Düzce Üniversitesi Bilim ve Teknoloji Dergisi, c. 8, s. 4, ss. 2344-2365, 2020.

[15] K. Nagarajan ve P. Natarajan, "Design of Structures" E-Notes of DSS-1, International Institute of Technology \& Management, Murthal Sonepat.

[16] M. D. Engelhardt, CE 335 Elements of Steel Design, Ders Notlarl, Austin, 2020. 